\begin{tabular}{|l|l|l|l|l|l|}
\hline MUNIBE Antropologia-Arkeologia & $n^{0} 71$ & $243-256$ & DONOSTIA & 2020 & ISSN $1132-2217 \cdot$ elSSN $2172-4555$ \\
\hline
\end{tabular}

\title{
Arqueología de la Primera Guerra Carlista (1833-1839): Una introducción
}

\author{
First Carlist War Archaeology (1833-1839): An introduction
}

PALABRAS CLAVES: Arqueología del conflicto, fortificación, asedio, batalla.

GAKO-HITZAK: Gatazkaren arkeologia, gotorleku, setio, guda.

KEY WORDS: Modern Conflict Archaeology, fortification, siege, battle.

\section{Gorka MARTÍN ETXEBARRIA(1)}

\section{RESUMEN}

El estallido y largo desarrollo de la I Guerra Carlista (1833-1839) supuso la construcción de una amplia variedad de elementos que a día de hoy constituyen un rico patrimonio arquitectónico y arqueológico: Durante los más de 7 años de guerra, carlistas y liberales recurrieron a la construcción de fuertes, trincheras, campamentos, torres... para alzarse con la victoria. La guerra no solo creó elementos ex novo, sino que muchos yacimientos de cronologías anteriores fueron modificados por el conflicto. A pesar de su multiplicidad, buen estado de conservación e importancia histórica, la arqueología apenas ha estudiado la realidad material de la I Guerra Carlista. Para suplir en parte esta carencia se realiza un primer estudio de conjunto de varios yacimientos de dicho contexto en la Comunidad Autónoma del País Vasco.

\section{LABURPENA}

Lehen Gerra Karlistaren (1833-1839) zehar hainbat elementu eraiki ziren, gaur egun ondare hetereogeneo eta aberats bat osatzen dutenak: Gerrak iraun zuen 7 urte baino gehiagotan karlistek eta liberalek hainbat gotorleku, forte, lubaki, kanpamentu... eraiki zituzten bestea garaitzeko asmoz. Gatazkak ez zuen soilik elementu berrien sorrera ekarri, aurreko kronologiako hainbat aztarnategietan ere eragina izan zuen. Ugariak, ondo kontserbatutak eta garrantzi historiko handikoak izan arren, arkeologiak nekez ikertu du Lehen Gerra Karlistako materialtasuna. Gabezi hau betetzeko lehen hurbilketa bat egiten da Euskal Autonomia Erkidegoko garai horretako zenbait aztarnetegi hastertuz.

\section{ABSTRACT}

In 1833, the death of King Fernando VII of Spain led to a dynastic crisis that quickly ran into a civil war, the First Carlist War or Seven Years War (1833-1839). It was a hard, violent and bloody conflict between Carlists and Liberals and in which the civil population was involved. It finished in 1839 with an agreement between the liberal general Espartero and the Carlist Maroto, but in fact, it supposed the victory of the liberals. Many Carlists felt betrayed and marched into exile. Carlism continued going against the liberal government of Madrid from inside and outside Spain, and there would be two more civil wars in 1846, 1872 and several coup d'etats.

During the conflict, both sides disrupted the landscape, constructing a large variety of elements: forts, trenches, encampments, fortresses, walls, towers... with the main goal of achieving the victory. The war transformed the appearance of cities and villages and it influenced not only the front line but also at the rear. The conflict not only created new elements, it also affected sites of previous chronologies, creating important stratigraphic phases that supposed the complete transformation of these sites. Nowadays, some of those elements survive and are part of a richly constructed and archaeological heritage.

In spite of their abundance, good state of preservation and historical importance, archaeology has not studied the materiality of the First Carlist War. Moreover, most of the elements that survive today are in danger because of the general ignorance about them and the lack of study and preservation strategies. In order to make up for this lack, a first global study of the First Carlist War archaeology is made in this article, based on the analysis of four archaeological sites of that context: the monasteries of San José de la Isla and San Francisco and the medieval villages of Peñacerrada and Salvatierra.

\section{INTRODUCCIÓN}

Las revoluciones americana (1776) y francesa (1789) desencadenaron importantes ciclos revolucionarios en Europa y América que supusieron profundos cambios en la mayoría de los países del mundo occidental. En países como Austria, Prusia, España, Por- tugal, Polonia, los Países Bajos, la península italiana o los estados alemanes tuvieron lugar cambios dinásticos y/o políticos, nuevas formas de soberanía, ensayos constitucionales, modificaciones fronterizas, anexiones... (Fusi, 2009, pág. 9). En América, la implantación de la revolución liberal vino acompañada de la independencia de la mayoría de las antiguas colonias.

\footnotetext{
(1) Investigador predoctoral de la Universidad del País Vasco (UPV/EHU). Grupo de Investigación en Patrimonio Construido. Edificio Micaela Portilla, Justo Vélez de Elorriaga Kalea, 1, 01006. gorka.martin@ehu.eus
} 
La transición del Antiguo Régimen al régimen liberal no fue un proceso lineal ni homogéneo. Existieron periodos de reacción y conservadurismo e implosiones revolucionarias que, con menor o mayor éxito, se extendieron geográficamente. La violencia estuvo presente durante la mayor parte del periodo, los pronunciamientos militares, las guerras civiles, las intervenciones internacionales y las represiones políticas estaban a la orden del día. España participó de las mismas dinámicas globales y la implantación de su particular revolución liberal (indefinida, incompleta y discontinua) estuvo marcada por ensayos constitucionales, experiencias contrarrevolucionarias y dos largas guerras (Fusi, 2009, pág. 10), la de Independencia (1808-1814) y la que será objeto de este artículo, la Primera Guerra Carlista (1833-1840).

Los teatros de operaciones principales fueron el Norte (País Vasco y Navarra), el Centro (sur de Teruel y norte de Castellón) y Catalunya, aunque mediante las expediciones carlistas se logró extender el conflicto a otras zonas de la Península. Durante el transcurso de la misma el paisaje fue alterado notablemente, ambos bandos construyeron gran cantidad de fuertes ${ }^{1}$, trincheras, campamentos, reductos... y dejaron su impronta en el registro material. La ausencia de planes de investigación concretos y propios sobre la investigación arqueológica de la Primera Guerra Carlista nos lleva a analizar en estas líneas las posibilidades de la misma a través de varios ejemplos arqueológicos documentados en el País Vasco.

\section{ESTADO DE LA CUESTIÓN: UNA TAREA PENDIENTE}

La arqueología del conflicto es la disciplina que estudia las guerras desde la materialidad que generaron. En el plano internacional cuenta con una repercusión amplia y de gran calado académico que ha cristalizado en la existencia de una revista monográfica de impacto, Journal of Conflict Archaeology y de una abundante producción científica (Saunders \& Cornish, 2019; Schofield 2006 o González-Ruibal, 2018). A pesar de que la mayoría de estudios se centran en el siglo XX, también los hay sobre el anterior, destacando los realizados en América Latina, donde los arqueólogos llevan tiempo estudiando las guerras del siglo XIX, tanto civiles como internacionales. Algunos casos son la Guerra del Paraná (VV.AA., 2014), guerra mejicano-estadounidense de 1846-1848 (VV.AA., 2020), Guerra de la Triple Alianza (Pintos, 2020), Guerra del Salitre (Zamorano, 2020) o Guerra de 1898 (VV.AA., 2014). Además, se han publicado importantes obras colectivas con estados de la cuestión, marcos teóricos y propuestas metodológicas que a día de hoy son referencia para cualquier estudio de este tipo (Landa \& Hernández de Lara 2014 y 2020). Otros ejemplos son la Guerra de Secesión Americana (Geier \& Potter, 2001; Geier, Scott, \& Babits 2014 o Geier \& Winter 1994), las guerras indias (Scott \& Fox, 1987 o Barnard 1998), la guerra anglo-estadounidense de 1812 (Cornelison \& Cooper, 2002) o las guerras napoleónicas (Jankauskas, Signoli, \& Miliauskienè 2006 o Rua, Gonçalves, \& Figueiredo 2013).

En España, tras varios años de tardanza, la arqueología del conflicto ha implosionado con un gran número de contribuciones, fundamentalmente centradas en la Guerra Civil Española de 1936 (González-Ruibal, 2016 y 2020), aunque también existen estudios sobre la Guerra de la Independencia (Suárez \& Álvarez, 2016 o VV.AA., 2017), la Guerra de Sucesión Española (Rubio \& Hernández-Cardona, 2012) o el maquis de la postguerra (Pujol, 2017 \& Morín, 2004). Respecto a las guerras carlistas, éstas se han venido tratando exclusivamente desde las fuentes escritas (Roldán, Martín \& Escribano, 2019 págs. 709-710) aunque en los últimos tiempos se observa un cambio de tendencia. Los restos que mayor y más temprana atención han recibido son las fortificaciones de grandes dimensiones, (Sáez-García, 2011; Moraza, Buces, \& García-Dalmau 2012 o Arrieta, 2015), aunque seguía predominando la perspectiva documental. A raíz de estos primeros acercamientos se han excavado fuertes como el de Zumalakarregi en Andoain (Buces \& Moraza, 2011). Ya en 2015 se realizaba un primer diagnóstico del estado de la cuestión de la arqueología del conflicto carlista en la CAPV y Navarra (Roldán \& Escribano, 2015) y a modo de síntesis los autores concluían lo siguiente:

El estudio arqueológico de las guerras civiles del siglo XIX no es un tema nuevo /.../ pero que todavía no se ha acometido de forma sistemática. La mayoría de los trabajos se han desarrollado al amparo de las leyes de patrimonio o gracias a iniciativas particulares, y no como fruto de líneas de investigación centradas en el carlismo (Roldán \& Escribano 2015, pág. 135).

En los cinco años que separan ese análisis, los trabajos arqueológicos sobre las guerras carlistas han ido en aumento, aunque se mantiene la predisposición hacia el patrimonio de mayor monumentalidad y de la Última Guerra Carlista (1872-1876). Así destacan los trabajos de Roldán y Escribano en la zona de Estella (2015 y 2017), los del autor en la zona de Bilbao (Martín, 2017 y 2019) y como un hito, la primera publicación sobre arqueología del conflicto carlista en una revista internacional (Roldán, Martín, \& Escribano, 2019). Este interés también se va extendiendo por otras geografías como Castellón (González-García, 2019) o Valencia (Navalón \& Guimaraens, 2016).

\footnotetext{
1 Para conocer los detalles y características de este tipo de fortificaciones véase Sáez-García, 2001; 2011; y Arrieta, 2015.
} 
La arqueología del conflicto apenas lleva una década de implantación en España, si bien se han realizado importantes avances en conflictos como la Guerra Civil, aún quedan importantes lagunas, un caso paradigmático es el de las guerras carlistas. Hasta la fecha han sido tratadas casi exclusivamente desde las fuentes escritas, las razones que pueden explicar estas ausencias han sido apuntadas por otros (Navalón \& Guimaraens, 2016, págs. 124-127) y pueden resumirse en: a) la ausencia de una memoria viva (como si existe en el caso de la Guerra Civil) que ha conllevado la amnesia social y académica respecto a estos conflictos, b) la invisibilización del patrimonio que generó, c) la tardía implementación de la disciplina en el panorama estatal y d) el profundo trauma causado por la Guerra Civil de 1936 que ha centrado (y continúa haciéndolo) buena parte de las atenciones de los arqueólogos y del debate público.

\section{ARQUEOLOGÍA DE LA PRIMERA GUERRA CARLISTA}

Por esta razón, nuestro objetivo es realizar una primera aproximación de conjunto al conocimiento material de la Primera Guerra Carlista a través de los yacimientos de San José de la Isla, San Francisco y las villas de Peñacerrada y Salvatierra. Los hemos seleccionado porque conservaban contextos estratigráficos claramente atribuibles a este conflicto. Los dos primeros ejemplos han sido excavados dentro de lo que se denomina "arqueología de urgencia", por lo que se trata de intervenciones realizadas como consecuencia de obras de construcción. Por otro lado, el objetivo de las intervenciones en el castillo de Peñacerrada y murallas de Agurain era recuperar contextos medievales. Las fuentes que hemos empleado han sido los informes preliminares, memorias técnicas de intervención y los materiales arqueológicos depositados en los museos.

\subsection{Convento de San José de la Isla (Sestao)}

El convento de San José de la Isla se ubicaba en la zona conocida como "El Desierto" en la ribera de Sestao. Data del siglo XVIII y fue construido por los padres carmelitas. Durante los años 2005, 2006 y 2010 fue objeto de una excavación arqueológica que documentó, entre otras, una fase importante relacionada con la I Guerra Carlista (Aníbarro, 2005, 2006 \& Aurrekoetxea, 2010).

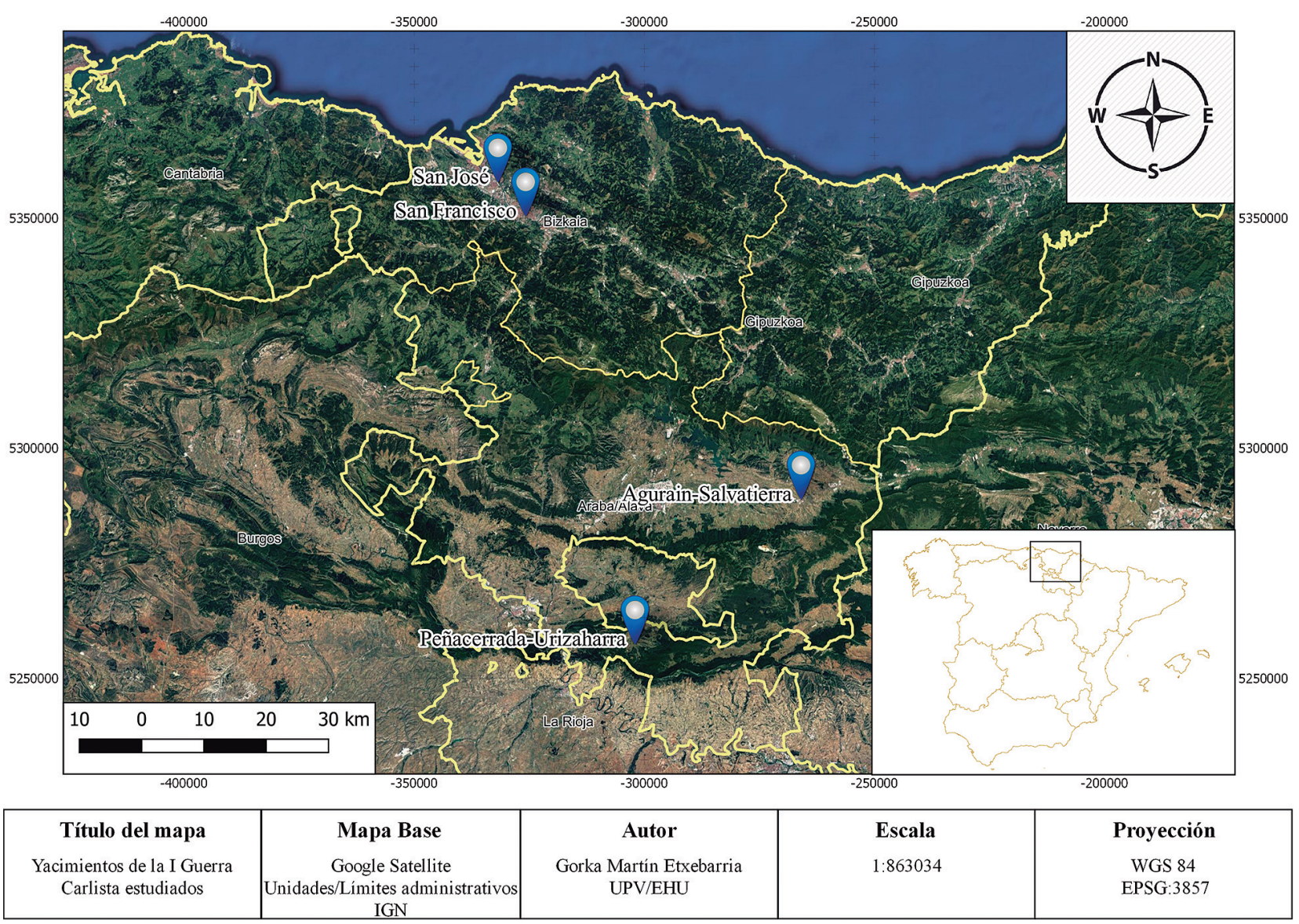

Fig.1. Ubicación geográfica de los yacimientos estudiados. Fuente: El autor. / Geographic location of the archaeological sites. Source: Author. 
Los expedientes documentales conservados indican que la Guerra de la Independencia (1808-1814) afectó a la comunidad monástica: su número se vio reducido ${ }^{2}$ y tuvieron que proveer de suministros a los franceses $^{3}$. Testigo material de esta fase es el hallazgo de una moneda de 8 maravedís de José Napoleón Bonaparte. Según los testimonios materiales y documentales consultados, no parece que el edificio fuera militarizado en esta época.

El estallido de la I Guerra Carlista conllevo la fortificación y militarización del complejo por parte de los liberales, convirtiéndose en uno de los principales puntos de defensa de Bilbao frente a los carlistas. Su ubicación, en uno de los pocos puntos elevados de la orilla de la ría, en la confluencia de ésta con el río Galindo y su fácil defensa por tierra, lo convertían en una posición altamente estratégica. Las fuentes documentales ofrecen una clara descripción de las obras realizadas y de los elementos defensivos construidos (Haedera, 2006a, págs. 39-40).

Un botón nos informa de las tropas que guarnecieron este punto, se usó entre los años 1824-1841 y en él que se puede leer: $P$ (rovincia)L de COMPOSTELA. Pertenecía al batallón de Compostela de las Milicias Provinciales, una unidad reclutada específicamente para situaciones excepcionales que no formaban parte del ejército regular. Fue parte de la guarnición de Bilbao, y gracias a un hallazgo de iguales características en el fuerte de Kastilozar (Escribano, Roldán \& Martín 2016) se sabe que también actuaron como fuerza móvil. La guarnición se completaba con la presencia de una fuerza británica compuesta por varios marineros y el navío Sarracene (Haedera, 2011, pág. 20).

Los militares alteraron significativamente las estructuras conventuales. El lagar y la bodega fueron reconvertidos en estructuras defensivas mediante el desmonte de parte de su alzado, la apertura de nuevas entradas más accesibles y la construcción de aspilleras para fusilería, reutilizando para ello piezas de la antigua estructura. Esta zona ofrecía unas buenas condiciones para su uso militar ya que tanto el lagar como la bodega eran estructuras soterradas, por tanto, a resguardo de la artillería. El objetivo principal de este punto era controlar la vega del Desierto, que durante la guerra era "el mejor y más profundo fondeadero del Nervión” (Haedera, 2006a, pág. 40).

La modificación de las estructuras conventuales, sobre todo la distribución interna de ciertos espacios, es una constante en el yacimiento, y suele acompañarse de la reutilización de piezas labradas del edificio religioso. Las nuevas obras son de escasa calidad técnica y se apoyan o cortan las previas (Haedera, 2011, pág. 41). Lo más seguro es que estas acciones se deban a la necesidad de alojar a la guarnición y proteger sus desplazamientos de la artillería y fusilería enemigas. Un buen ejemplo es el reacondicionamiento realizado en el antiguo refectorio, reconvertido en caballerizas (Haedera, 2006b, pág. 11), en donde se hallaron dos estribos metálicos. A mi parecer, el escaso tamaño del lugar indica que aquí se alojarían las monturas de los oficiales o las necesarias para el aprovisionamiento del destacamento, en cualquier caso, no existiría una fuerza de caballería propia.

En el sector oriental se documentaron evidencias de la fortificación del convento. Se trata de dos grandes zanjas que cortaban elementos estructurales anteriores y que, por sus dimensiones (más de 14 metros de longitud y 1,5 metros de anchura), parecen corresponderse con un foso al interior del recinto. El hallazgo de multitud de clavos metálicos, una piqueta metálica con la cabeza en forma de aro (presumiblemente para pasar una cuerda) y la cabeza de un pico, son el testimonio material de los continuos trabajos de fortificación que se realizaban.

Sabemos que la plaza contó con artillería para su defensa ya que se recuperaron dos balas rasas de hierro macizo con un diámetro aproximado de 14 centímetros, que probablemente fueron usadas para los cañones lisos de avancarga del 14. Estos materiales se relacionan directamente con el baluarte exhumado en 2010, se trata de una construcción de mampostería con refuerzo de sillería en los esquinales (Haedera, 2011, págs. 18-19) de muros bajos, anchos y en perfil de pirámide truncada. Según las fuentes escritas contaría con dos cañones del 32 y uno del 9 (Haedera, 2006a, págs. 39-40). La nueva construcción sigue el típico esquema defensivo abaluartado que dominaba en la época, pensado para resistir lo mejor posible los impactos de artillería. También se documentaron una serie de improntas metálicas alineadas al frente de la batería que se corresponderían con una fila de toneles de madera a modo de protección auxiliar, algo que era de lo más habitual y que aparece reflejado fotográficamente en el asedio de Bilbao de 1874.

El foso tenía un perfil en -V- de fondo plano con una anchura de 3,10 metros en su parte alta, 0,70 en la baja y un desnivel aproximado de 1,50. Se ubicaba a unos 4 metros del muro de la batería y rodeaba el complejo por los lados oeste y sur. En 2006 fue descubierto parcialmente, pero en este caso presentaba un muro de mampostería de mala calidad hacia la cara interna (Haedera, 2006b, pág. 10), que podría servir de asiento al puente levadizo que daba acceso al fuerte. También se documentó una segunda zanja a unos 8,5 metros del talud, que si bien era coetánea al foso (Haedera, 2011, pág. 26) no se relacionaba con él, los arqueólogos desco-

\footnotetext{
2 Archivo Histórico Foral de Bizkaia. Administración. Gobierno y Asuntos Eclesiásticos. AJ01351/004.

${ }^{3}$ Archivo Histórico Foral de Bizkaia. Administración. Seguridad Pública, Guerras y Servicio Militar. AQ00974/007.
} 

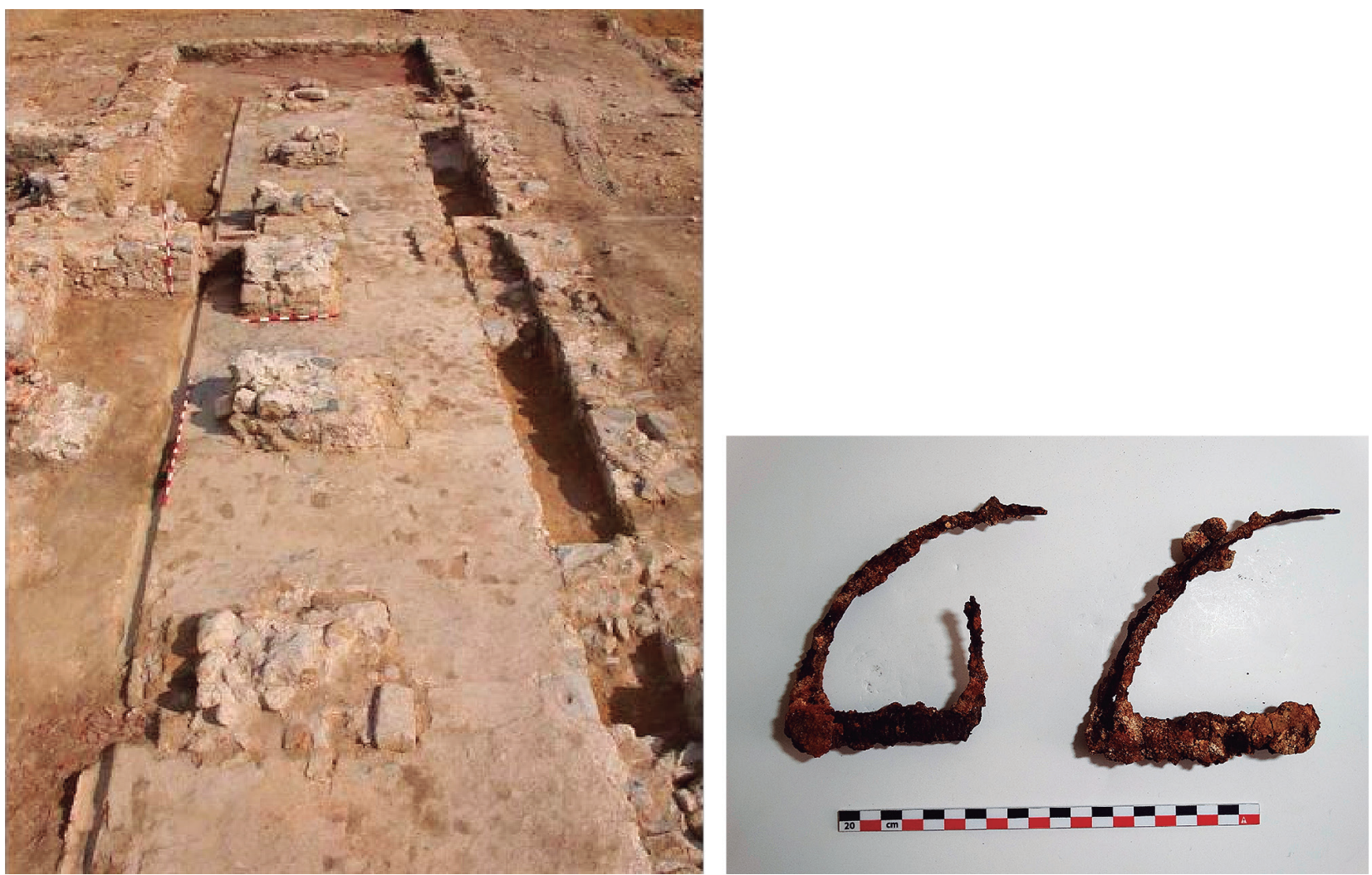

Fig.2. Izquierda: Antiguo refectorio conventual convertido en caballerizas. Fuente Haedera 2006 b, pág. 11. Derecha: posibles estribos metálicos de caballería. Fuente: El autor. / Left: Ancient conventual refectory transformed into stable. Source: Haedera, 2006 b pág. 11. Right: Metalic stirrups. Source: Author.
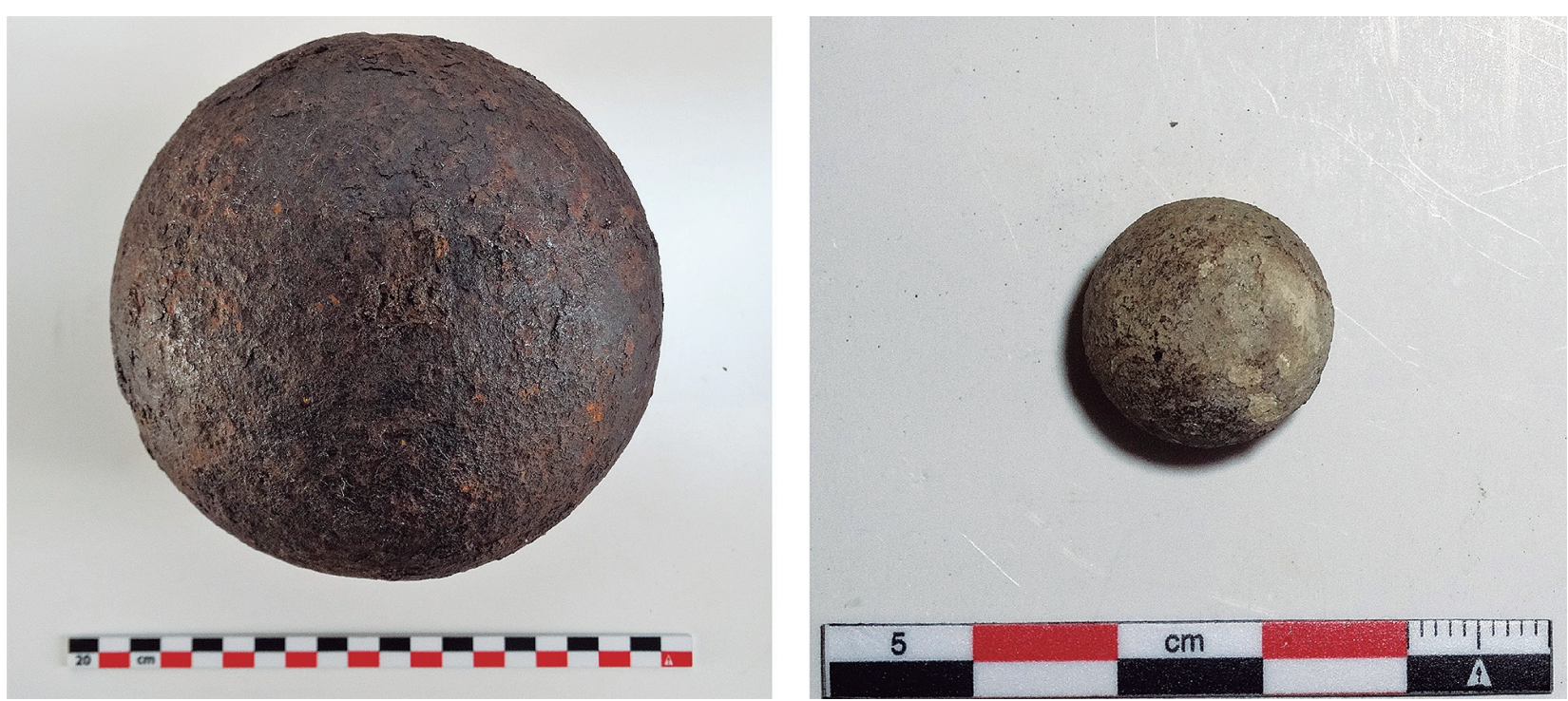

Fig.3. Izquierda: Bala rasa para cañón de avancarga. Derecha: Bala de avancarga para mosquete. Fuente: El autor. / Left: Cannonball for muzzle-loading gun. Right: Bullet for muzzle-loading musket. Source: Author.

nocían su función, aunque posiblemente se trataría de algún tipo de defensa avanzada a modo de trinchera. En la esquina noroeste el foso formaba una -S-, adaptándose a una segunda estructura militar gravemente afectada por las obras de 2006 y que se correspondía con una segunda batería de planta circular de la que no se tenían referencias escritas (Haedera, 2011, pág. 28).

Las obras de fortificación no siempre destruyeron las estructuras previas, sino que respetaron y aprovecharon aquellas que pudieran servirles. Es el caso del 

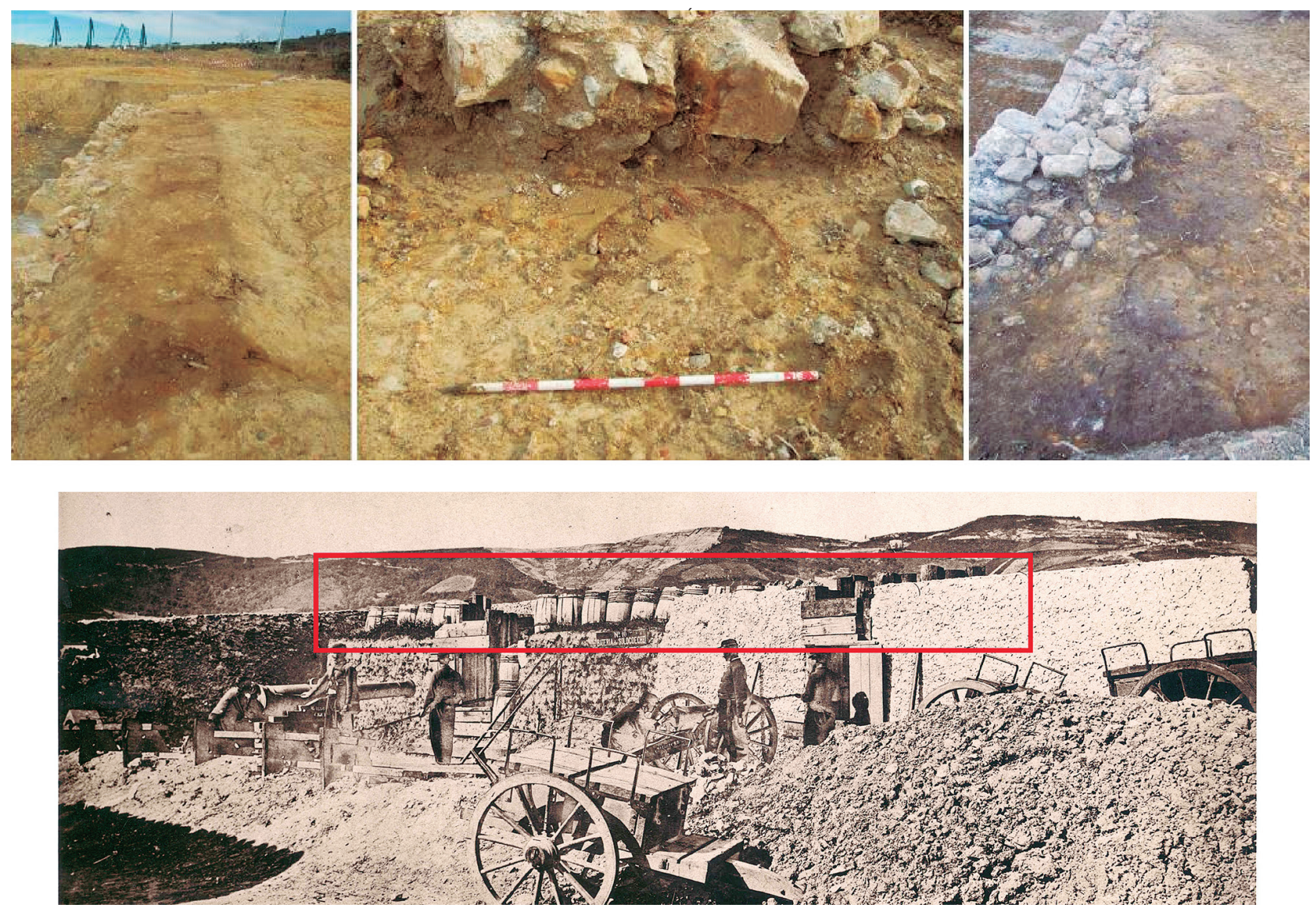

Fig.4. Superior: Improntas de los flejes de barriles y toneles al frente de la batería. Fuente: Haedera 2010, pág. 24. Inferior: Fotografía de la batería de la Sendeja durante el asedio de Bilbao de 1874. Fuente: Modificado de Archivo Histórico Foral de Bizkaia, Fotografía, Álbum de Charles Monney, AL0011-0030. / Upper: Barrels marks in front of the battery. Source: Haedera, 2006 pág. 24. Lower: Photograph of the Sendeja battery during the Bilbao siege in 1874. Source: Modified of Archivo Histórico Foral de Bizkaia, Fotografía, Álbum de Charles Monney, AL0011-0030.

complejo sistema de captación de aguas que desarroIlaron los monjes (Haedera, 2006a, pág. 42 y ss.) y que los liberales reutilizaron al fortificar el convento. El uso de la cisterna en esta fase queda atestiguado por la apertura de un nuevo vano de acceso y tres escalones de madera en la entrada (Haedera, 2006b, págs. 21-22). El disponer de agua potable era uno de los elementos más importantes para hacer frente a un asedio prolongado, de esta manera, las obras de la época conventual hacian autosuficiente a la guarnición del Desierto, capaz de resistir, llegado el caso, un largo sitio.

Aunque en un primer momento los arqueólogos dudan de su adscripción cronológica concreta, Primera o Última Guerra Carlista (Haedera, 2011, pág. 21), la batería principal ya aparece en un plano de 1848 tal y como fue documentada en la excavación; mientras que en uno de 1876 ya está desaparecida. Además, la ausencia de materiales bélicos del periodo 1872-1876, caracterizado ya por el empleo de cartuchos metálicos y sistemas de retrocarga tanto para la artillería como para la fusilería (Roldán, Martín \& Escribano 2019, pág. 714 y 715), viene a corroborar que se trataría de una fortificación anterior.

La cultura material recuperada evidencia una larga ocupación militar del entorno. Las obras en el refectorio y los estribos hallados muestran el estacionamiento de monturas durante cierto tiempo. También se recuperaron numerosas piedras de fusil, algunas de ellas con fracturas en la parte frontal producidas por el uso del mecanismo, por tanto, se trataría de piezas desechadas. Lo que nos lleva a la conclusión de que en esta posición se hizo fuego durante el tiempo suficiente como para estropearlas. El bagaje militar lo completan varias balas de avancarga para mosquete.

La presencia de objetos personales de los soldados nos permite asomarnos a su vida diaria. Fumaban tabaco en pipa, así lo atestiguan siete fragmentos de pipas de caolín, muy populares durante todo el siglo XIX. Aunque su estado de conservación dificulta su caracterización concreta, el hallazgo de una navaja plegable podría estar relacionado con el aseo personal del soldado; también podría ser un objeto de uso cotidiano, de lo que no hay duda es de que es un objeto personal, no militar. Una pequeña medalla de San Francisco nos refiere a la religiosidad del individuo y respecto a la indumentaria, aparte del botón mencionado previamente, también se recuperaron otros metálicos, de hueso, planos y cóncavos. Por último, habría que mencionar varias monedas que su deficiente estado de conservación impide adscribir cronológicamente. 

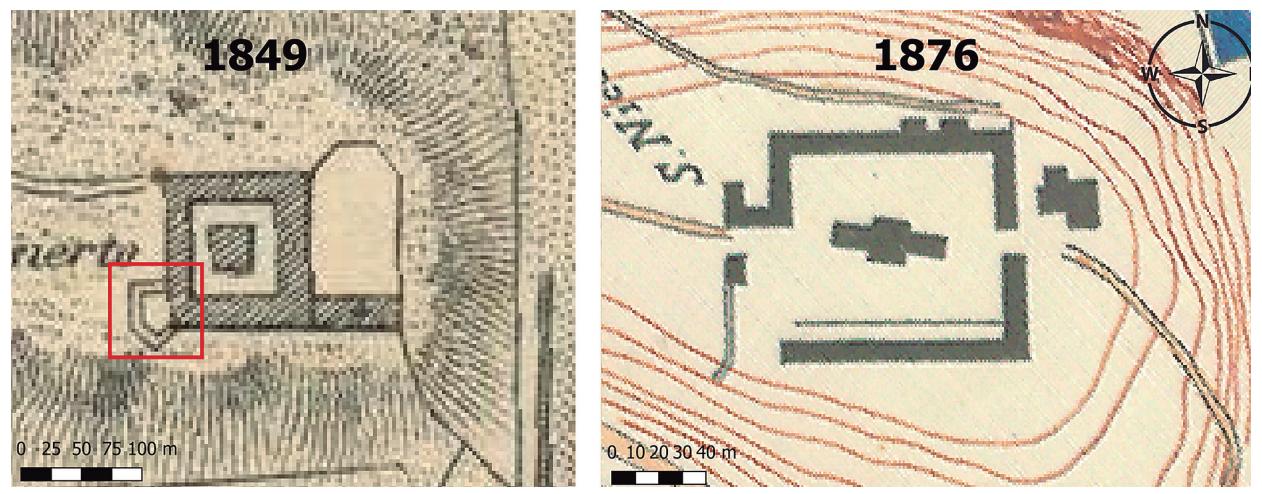

Fig.5. Izquierda: Convento de San Nicolás del Desierto en 1849, el recuadro rojo se corresponde con la batería excavada en 2010. Fuente: Modificado de Plano de la Concha y Barra de Bilbao y del río Nervión desde su desembocadura hasta dicha villa, Cartoteca del IGN. Derecha: Convento de San Nicolás del Desierto en 1876. Fuente: España. Ministerio de Defensa. Instituto de Historia y Cultura Militar. Archivo General Militar de Madrid. BI 03-10 / Left: San Nicolas del Desierto monastery in 1849, the red rectangle marks the place where the archaeologist found the artillery battery in 2010. Source: Modified of Plano de la Concha y Barra de Bilbao y del río Nervión desde su desembocadura hasta dicha villa, Cartoteca del IGN. Right: San Nicolas del Desierto monastery in 1876. Source: España. Ministerio de Defensa. Instituto de Historia y Cultura Militar. Archivo General Militar de Madrid.BI 03-10.
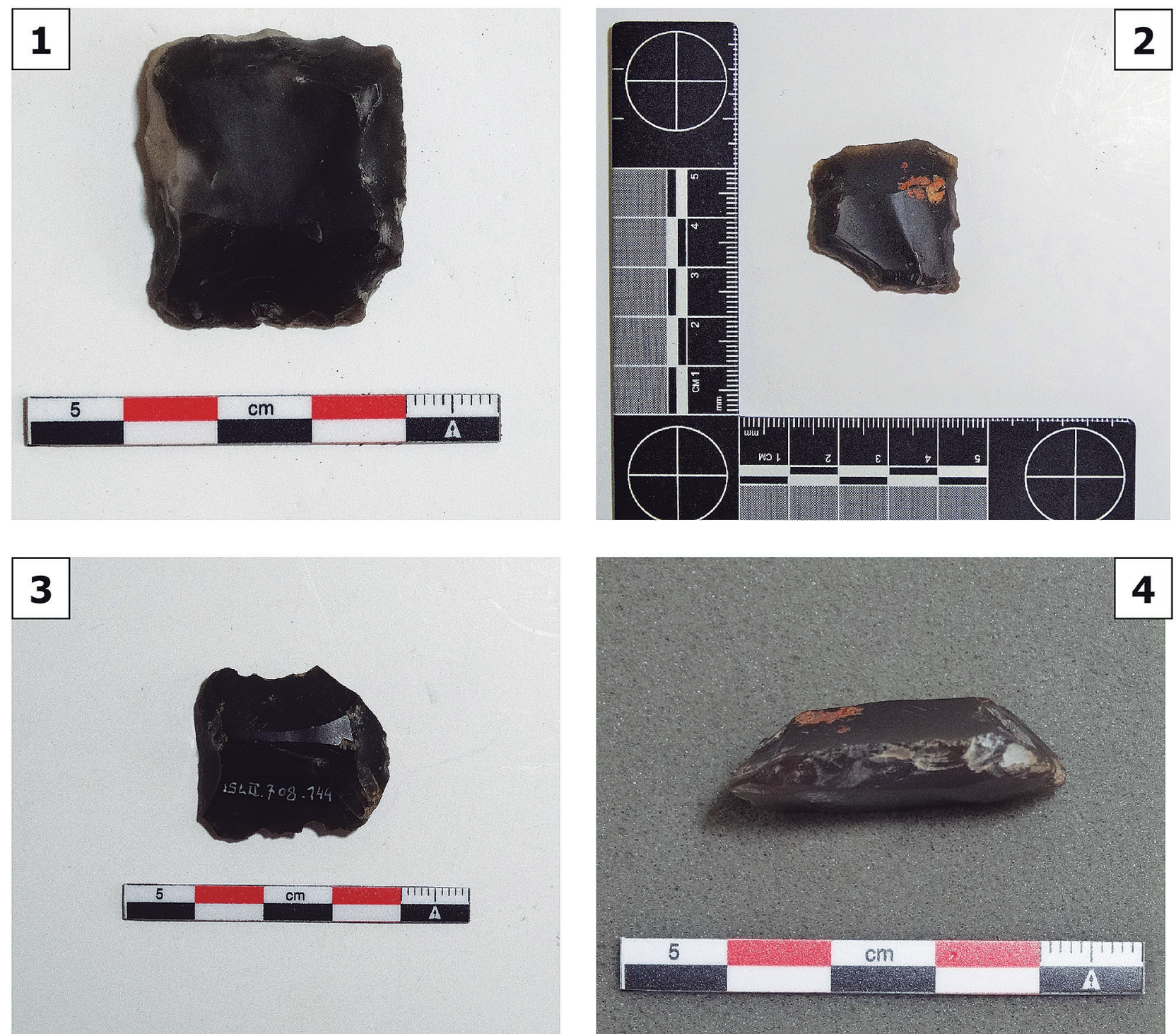

Fig.6. Varias piedras de fusil. La número 2 muestra una fractura en la parte inferior izquierda, la 4 muestra la vista que accionaría el mecanismo de ignición. Fuente: El autor. / A group of flints. The number 2 is broken and number 4 shows the principal view of the mechanism. Source: Author. 

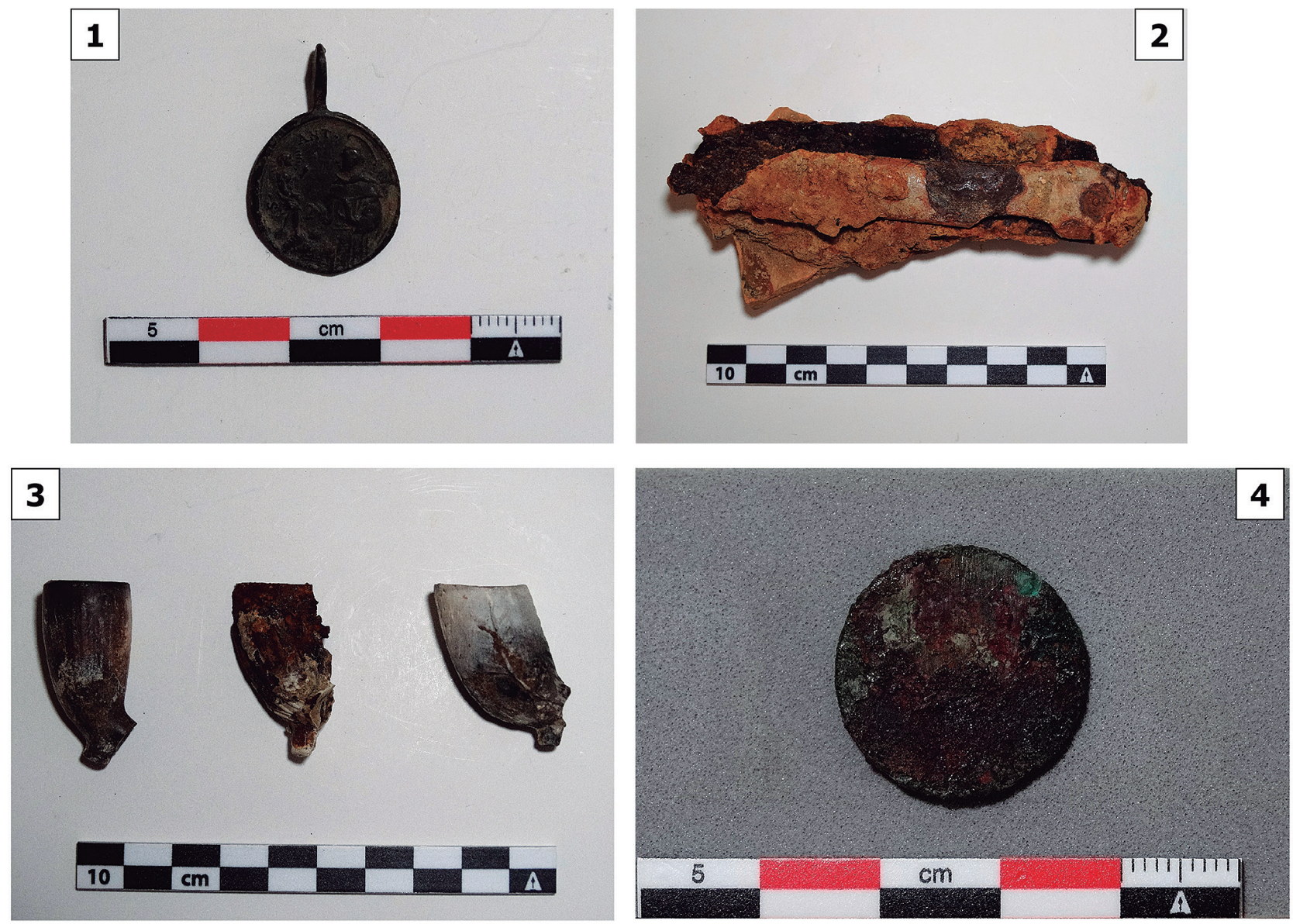

Fig.7. 1: Medalla de San Francisco. 2: Navaja plegable. 3: Cazoletas de pipa caolín. 4: Moneda indefinida. Fuente: El autor. / 1: San Francisco medallion. 2: Folding blade. 3: Caolin pipes bowls. 4: Undefined coin. Source: Author.

En síntesis, se puede decir que los militares liberales ocuparon el antiguo convento de San José de la Isla modificando gran parte de sus estructuras a la funcionalidad castrense. Las obras realizadas en la bodega y lagar responderían a un primer momento en el que es apremiante fortificar el edificio lo mejor que se pueda en un corto espacio de tiempo, por ello se recurrió a una estructura que ya de por sí ofrecía cierta protección, abriendo aspilleras para hacerla defendible. En un momento posterior, cuando el punto ya se convirtió en una fortificación estable con guarnición permanente, se realizaron unas nuevas obras de carácter puramente militar, con la construcción de dos baterías y un foso perimetral, que, no obstante, se adaptaba al sistema de captación de aguas prexistente para aprovecharlo. El proceso de militarización se complementó con la reestructuración interna de varios espacios conventuales.

Tras la guerra el convento quedó abandonado definitivamente antes de $1851^{4}$. En 1873, durante la Última Guerra Carlista, la junta de Armamento y Defensa de
Billbao acordará fortificar el Desierto, pero la guarnición se rendirá rápidamente a los carlistas el 23 enero de 1874 (Haedera, 2011, pág. 21). Finalmente, en 18791882 en el solar se construyó la fábrica de San Francisco (Haedera, 2006a, pág. 30 ) arrasando con los restos que pudieran quedar del conveto.

\subsection{Convento de San Francisco (Bilbao)}

El convento de San Francisco, ubicado en lo que hoy es Bilbao la Vieja, fue excavado durante los años 2006, 2007 y 2009 (Neira, 2006, 2007 y Neira \& Novoa, 2008). En la Guerra de la Independencia fue ocupado por los militares que lo emplearon como cuartel (Martín, 2019, pág. 43), algo que se repetirá en la I Guerra Carlista.

En los asedios de Bilbao de 1835 y 1836 las tropas liberales se instalaron aquí modificando gran parte de sus estructuras: "acondicionaron y reformaron espacios para el almacenamiento de camas, suministro de

\footnotetext{
${ }^{4}$ Archivo Histórico Foral de Bizkaia. Municipal. SESTAO 0205/076.
} 
camas, trabajos de limpieza y recomposición de excusados" (QARK, 2010, pág. 276).

En el transcurso de las excavaciones se identificaron los restos de un gran incendio en la capilla que se interpretó como "los restos de ignición de algún horno de albañilería” (QARK, 2010, pág. 79). Sin embargo, el diario del jefe militar del puesto especifica que aquí se ubicaba el polvorín y que el impacto de un proyectil carlista provocó una gran explosión ${ }^{5}$, por lo que las evidencias de ignición pudieran corresponderse con este suceso. En la capilla 2 sur se ubicaban los restos de las cocinas para la tropa: Las paredes mostraban signos de rubefacción, y se documentó un hogar con carbones y escoria de hierro, así mismo, en el interior de una de las tumbas se halló una olla metálica (QARK, 2010, pág. 91).

La guarnición modificó la distribución interna de varios espacios. En general se trataron de obras baja calidad técnica realizadas con ladrillos sacados del encajonado de la iglesia consistentes en el cerramiento de vanos demasiado expuestos y la apertura de nuevos accesos para ofrecer la menor superficie de exposición a los proyectiles enemigos (QARK, 2010, pág. 110-114 y 168).

La modificación más interesante fue la conversión de la sala de terciarios en una pequeña fundición de balas de avancarga (QARK, 2010, pág. 224). La tecnología bélica de la época permitía el autoabastecimiento de las tropas en cuanto al municionamiento de armamento ligero. Algo que en el conflicto siguiente ya no será posible y jugará en contra de los carlistas (Roldán, Martín \& Escribano 2019, pág. 706).

A esta fase también corresponde la habilitación de la pared occidental de la sala, cerca de la puerta de entrada, como caballerizas. Se abrieron nueve mechinales separados a unos dos metros de distancia donde se insertarían argollas o ganchos de hierro para sujetar los bocados de los animales. Por último, se documentaron una serie de agujeros de poste (QARK, 2010, pág. 225), que servirían para dividir el establo internamente mediante cuerdas atadas a los postes. Teniendo en cuenta las pequeñas dimensiones de este espacio, se correspondería, al igual que en San José de la Isla, con la estabulación de las monturas de los oficiales.

El cerramiento de vanos y creación de nuevos accesos conllevaron un cambio en la circulación entre los espacios, ahora condicionado por el contexto bélico. En general, las obras de reacondicionamiento se caracterizan por la recompartimentación del espacio, la pobreza en sus técnicas constructivas y el desmantelamiento de estructuras anteriores cuyos materiales son reaprovechados. Todo ello da muestra de la rapidez y premura con la que estas fortificaciones fueron rea- lizadas para adaptarlas lo antes posible a las nuevas necesidades.

Finalmente, los restos del convento que aún quedaban fueron arrasados para la construcción del cuartel de nueva planta del Príncipe Alfonso en 1861-1865. Durante el asedio de Bilbao de 1874 el edificio sufrirá el rigor del bombardeo carlista, convirtiéndose en uno de los objetivos principales de las baterías carlistas (Cuerpo del Estado Mayor del Ejército, 1885, págs. 520-521), pero eso ya escapa a la cronología que se ha marcado.

\subsection{Urizaharra-Peñacerrada}

Es una villa de origen medieval ubicada en la Montaña Alavesa, a unos 26 kilómetros al sur de Vitoria-Gasteiz. Durante la Primera Guerra Carlista el castillo medieval fue ocupado y fortificado por las tropas del Pretendiente y entre los días 20 y 22 de junio de 1838 hubo una importante batalla que finalizó con la posesión de la plaza por las tropas liberales de Espartero (Albi de la Cuesta, 2017, págs. 381-384). El primer objetivo de Espartero, que venía de Vitoria-Gasteiz, fue tomar el castillo antes de continuar hacia la villa. Tras un intenso bombardeo los sólidos y anchos muros de sillería resistieron y se intentaron métodos alternativos: el asalto con escalas, el incendio de las puertas y la excavación de minas, todos infructuosos. Finalmente se logró abrir brecha y el recinto fue asaltado y tomado por los liberales. Las tropas de Don Carlos se replegaron hacia el pueblo, donde volvieron a presentar resistencia (Albi de la Cuesta, 2017, págs. 381-382).

La excavación arqueológica de la ermita de Nuestra Señora de Urizaharra constató que para fortificar el castillo los carlistas se llevaron los sillares y vigas del templo, arrojando el mobiliario al suelo, donde permaneció allí hasta la excavación de 2011 (Ajamil, 2011, pág. 124). El desmantelamiento de ermitas fue algo común durante las guerras carlistas que incluso llegó a dejar testimonio gráfico (Pellicer,1875).

Un plano de la época nos ofrece una visión detallada de las características del castillo. La apariencia general no varió, es un ejemplo más de castillo medieval, formado por un recinto amurallado adaptado a la topografía en la que se asienta con cinco torres circulares en su recorrido. Únicamente en su lado sur se construyó un cuerpo de guardia aspillerado a modo de torre avanzada para guardar la entrada por este flanco. Al interior se organizaron las dependencias para la tropa, una plataforma para piezas de artillería y un paso de ronda que facilitaría el disparo de los fusiles (Plata \& Solaun, 2008, pág. 30). El sondeo 2 documentó la entrada a este cuerpo de guardia desde el alojamiento situado en el patio, ofreciendo un paso rápido desde

\footnotetext{
${ }^{5}$ Archivo Histórico Foral de Bizkaia. Administración. Seguridad Pública, Guerras y Servicio Militar. AQ01349/040.
} 

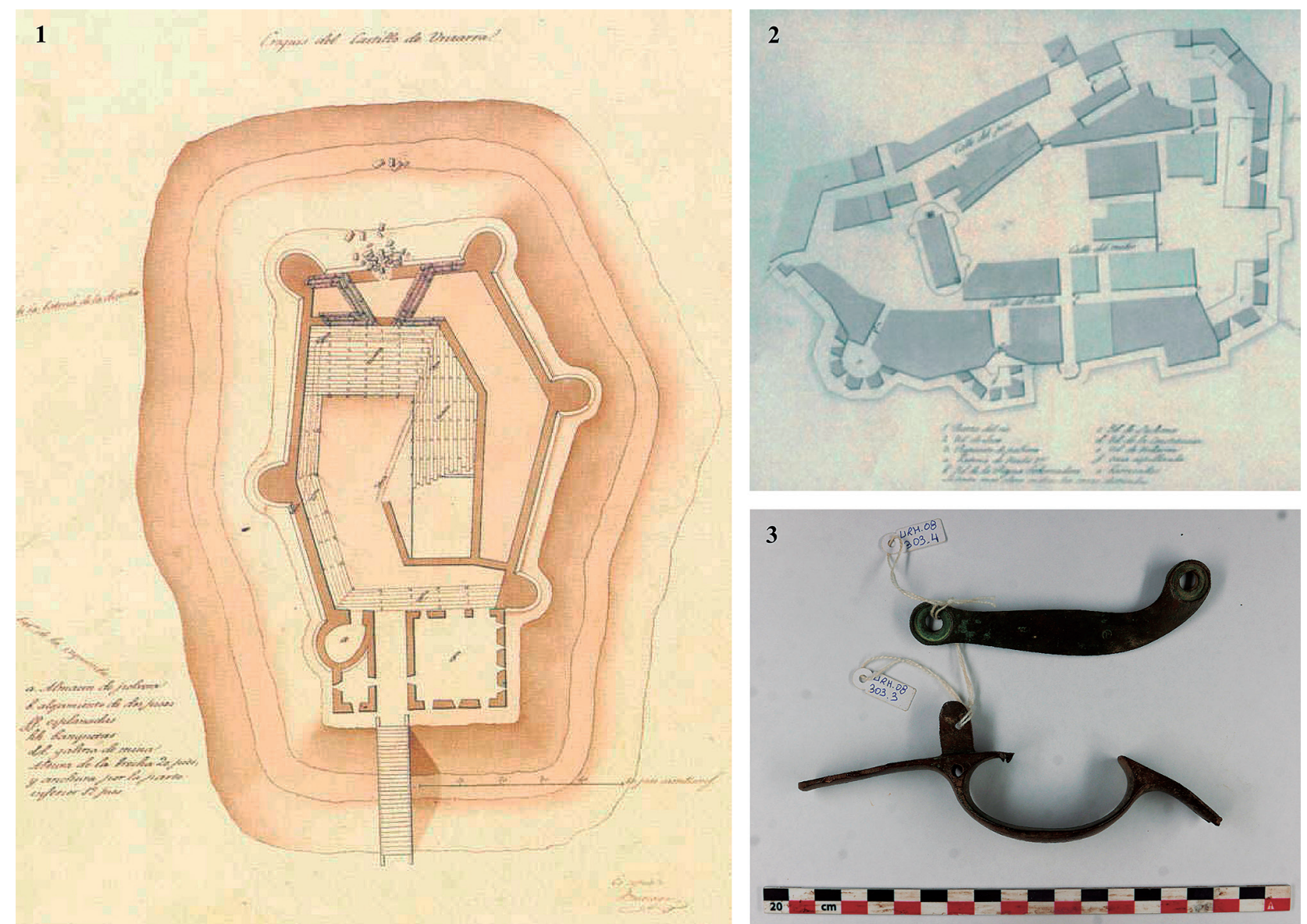

Fig.8. 1: Plano del castillo de Urizaharra fortificado por los carlistas. Fuente: Plata \& Solaun 2008, pág. 28. 2: Plano de la fortificación de la villa de Peñacerrada en 1838. Fuente: Álbum Siglo XIX 2020. 3: Dos piezas de mosquete recuperadas en la excavación del castillo de Peñacerrada. Fuente: El autor. / 1: Urizaharra castle map fortified by carlists. Source: Plata \& Solaun 2008, pág. 28. 2: Peñacerrada village map in 1838. Source: Álbum Siglo XIX 2020. 3: Two pieces of musket found in the Urizarra castle excavation. Source: Author.

los aposentos al puesto de combate. El sondeo 1 se realizó en estas dependencias e identificó los restos de un hogar. Por último, en el sondeo 3 se recuperaron varias piezas metálicas que formaban parte de un mosquete (Plata, 2016).

En un plano de la fortificación de Peñacerrada por los carlistas (Ajamil, 2003, pág. 49) se aprecia cómo la muralla norte y los torreones al este fueron aspillerados. Varias intervenciones arqueológicas han corroborado que los defensores emplearon la antigua cerca medieval abriendo aspilleras para su defensa (Fernández-Bordegarai \& Ajamil 2002, pág. 256). En el solar nº 15 de la calle Barón de Benasque, por ejemplo, se identificó un muro que se adosaba a la línea interior de la muralla y entre cuyos depósitos se recuperaron dos proyectiles de artillería (Varón, 2005, págs. 265-266). Se trata de fragmentos pertenecientes a una esfera de hierro hueca, lo que probablemente sería una granada disparada por una pieza lisa de avancarga, las armas con las que los liberales atacaron los muros y abrieron brecha.
La victoria liberal conllevó la destrucción de buena parte de la localidad por un gran incendio, la muralla quedó completamente arrasada en varios sectores (Ajami, 2003, pág. 48 y 51). Lo que llama la atención es que no fuera nuevamente edificada, como sí lo hicieron en Agurain-Salvatierra, la explicación pueda deberse a que los liberales, aprendida la dura lección de su conquista, quisieran dejar el pueblo indefenso. Esa suerte corrió el castillo de Gebara, el último reducto carlista de la Primera Guerra que fue, literalmente, "volado por los aires" (Albi de la Cuesta, 2017, pág. 454).

Durante la Última Guerra Carlista la población no sufrirá directamente los efectos de la guerra, pues Álava fue un teatro de operaciones secundario hasta 1875, salvando los asedios de Laguardia. No se han documentado contextos arqueológicos atribuibles a esa cronología ni las fuentes documentales consultadas mencionan operaciones en este sector. 


\subsection{Agurain-Salvatierra}

Agurain-Salvatierra es una villa de origen medieval situada en el oriente de Álava, a unos 27 kilómetros al este de Vitoria-Gasteiz. Como gran parte de las villas medievales contaba con una muralla con torreones que rodeaba su perímetro. Se han realizado varias excavaciones y estudios arqueológicos que han demostrado cómo la cerca fue desmantelada en gran parte por los carlistas en 1835 para reforzar el castillo medieval de Gebara ${ }^{6}$.

Las excavaciones del 2002 y 2003 en la calle Zapatari dejaron al descubierto parte de la cerca medieval "de sillería aparejada, con piezas de piedra caliza bastante uniformes, con la cara visible acabada en un repicado basto, unidas entre sí por argamasa de cal y arena" y el arranque de varios torreones (Fernández Bordegarai, 2002, pág. 266). Hacia la parte interna, las estructuras fueron arrasadas hasta la altura de 1,5 metros aproximadamente, hacia la externa el expolio fue mayor, conservándose tan solo una hilada de 25 centímetros de altura (Fernández Bordegarai, 2003, pág. 237). Estas excavaciones dan idea de la magnitud del expolio carlista, que al menos en el sector occidental llegó a desmantelar la mayor parte de la muralla hasta sus cimientos.

En 2004 se realizó una lectura estratigráfica completa de la fachada trasera del ayuntamiento, donde se encontraba un tramo de la muralla occidental. Presentaba una morfología diferente al del resto de la cerca, ya que tenía un perfil en ángulo y lienzos con ligero talud (Fernández Bordegarai, 2004, pág. 45), características propias de esquemas defensivos donde ya se ha introducido la artillería. Los arqueólogos concluyeron que la mayor parte del lienzo conservado hoy en día se correspondía con una refacción realizada después de la Primera Guerra Carlista, cuando se abandona el modelo de muro recto para adquirir un plano ascendente (Fernández Bordegarai, 2004, pág. 47).

El caso de Agurain-Salvatierra es un buen ejemplo de cómo el conflicto civil tuvo incidencia no sólo en los frentes de combate, sino también en poblaciones situadas en la retaguardia y de cómo la economía de guerra aprovecha cualquier recurso a su alcance, por muy arcaico que éste sea. En definitiva, buena parte de la cerca que se observa hoy en día se corresponde con una reconstrucción posterior a 1839 (Fernández Bordegarai, 1992 pág. 27). Al igual que en Peñacerrada, la Última Guerra Carlista no tuvo tanta incidencia en la villa, prueba de ello es la ausencia de restos materiales y noticias asociadas a esta cronología.

\section{RESULTADOS}

De lo expuesto anteriormente se pueden inferir varios datos interesantes:

Los yacimientos de San José de la Isla y San Francisco fueron modificados durante la guerra para hacer de ellos emplazamientos militares defendibles. En el primer caso se observa la transición de una posición eventual a permanente, pasando del aprovechamiento de estructuras previas y aspillerado de vanos, a la construcción de unas defensas de nueva planta según la poliorcética del momento; sin que ello implique que se abandonaran las primeras defensas. En el segundo caso esta transición no se observa de manera tan clara, aunque la presencia de una fundición para balas de plomo viene a corroborar una ocupación militar prolongada. Es probable que San Francisco tuviera una funcionalidad de acuartelamiento y no de punto defensivo.

En ambos casos los militares alteraron significativamente los cenobios, modificando su distribución interna mediante la construcción de muros y cerramiento/ abertura de nuevos vanos y accesos. Estas obras eran, por lo general, de escasa calidad técnica, empleaban los materiales de las fases anteriores y respondían a las necesidades surgidas del contexto bélico. Merece la pena destacar que la Primera Guerra Carlista fue, para ambos, la última fase de uso en la que aún se reconocían las estructuras originales.

La información arqueológica nos muestra lo que debió de suponer el día a día del soldado. Fumar tabaco en pipa debía ser uno de los pasatiempos más habituales para matar las largas horas de inactividad. Las obras de fortificación eran continuas, se pueden interpretar como una forma productiva de mantener a la tropa activa y también como el mantenimiento necesario ante el desgaste que suponía el alargamiento del conflicto. Las piedras de chispa desechadas evidencian que la guarnición, o bien mantenía combates con el enemigo, o se entrenaba constantemente. También se realizaban actividades productivas, como la fundición de balas de plomo. Por último, la documentación de enseres de cocina y hogares nos dice que el rancho se preparaba en el propio destacamento. Nos llama la atención que no se hayan recuperado recipientes que remitan al consumo de alcohol, algo que es omnipresente en los contextos bélicos contemporáneos.

Las consecuencias de la guerra fueron de gran calado para las villas de Peñacerrada y Salvatierra, donde buena parte de su muralla fue alterada en este momento. En el primer caso por acción directa de las operaciones militares, mientras que, en el segundo de manera indirecta, para fortificar el castillo medieval de Gebara. En síntesis, se puede decir que gran parte de la fisionomía actual de los cascos antiguos de ambas villas se origina en 1833-1839.

\footnotetext{
${ }^{6}$ Se dice que sacaron más de 10.000 carros de sillares. Fuente: (Ajamil, 2003, pág. 237).
} 


\section{CONCLUSIONES}

El denominador común de todos los yacimientos estudiados es que en origen se idearon para fines muy distintos. Por un lado, esto nos habla del profundo impacto de la guerra civil, que altera totalmente el paisaje del momento. Por otro lado, es una clara muestra de lo que supone la "economía de guerra", donde todo lo que se pueda aprovechar para vencer al enemigo se aprovecha, y más en el caso carlista, que siempre estuvieron en inferioridad de medios respecto a sus enemigos. Esta circunstancia les hizo fortificarse en castillos medievales, reforzarlos con sillares de una muralla también medieval o defender Peñacerrada desde su cerca del siglo XIV. Finalmente, de aquí se infiere que un futuro estudio arqueológico de la I Guerra Carlista no debe centrarse únicamente en elementos directamente atribuibles a la fecha, sino que también debería incluir contextos anteriores y no necesariamente militares que fueron empleados y alterados durante el transcurso de las operaciones.

Como se ha demostrado, la Primera Guerra Carlista generó sus propios contextos arqueológicos que se reflejan en la existencia de fases estratigráficas de entidad. El estudio de esta materialidad ha aportado datos novedosos respecto a los métodos de fortificación de la época, la vida cotidiana del soldado y el impacto de la guerra en el urbanismo de las villas vascas. A pesar de ello, a día de hoy no existe un estudio de conjunto de este patrimonio y apenas se han publicado resultados parciales. Las fuentes consultadas proceden de informes de excavación que, o bien se realizaron como consecuencia de obras de construcción (casos de San José, San Francisco y villa de Peñacerrada-Urizaharra) o bien enfocados en restos más antiguos (caso de castillo de Peñacerrada-Urizaharra y villa de Agurain-Salvatierra).

Esta arqueología tiene un potencial prometedor y una reseñable capacidad de crecimiento por varias razones. En primer lugar, por la existencia de yacimientos con información sobre el conflicto pero que todavía no han sido estudiados en profundidad, valga como ejemplo los restos de las fortificaciones carlistas y liberales en torno a Donostia (Sáez-García, 2001), de la destrucción del convento de Santa Catalina de Badaya (Saenz de Urturi, 2000) o de "El Fuerte" (Gil Zubillaga, 2001), ambos en Iruña de Oca. En segundo lugar, por la ausencia de estudios de conjunto que traten de explicar este importante suceso histórico a través de las fuentes materiales para crear discursos históricos novedosos, que se alejen de las perspectivas militaristas y políticas y que aporten una visión más social del conflicto. En tercer lugar, por ser un motor de sensibilización patrimonial que, a través de la difusión y la educación, evite pérdidas irreparables como la de la muralla liberal de Santander, destruida este mismo año.

Por todo ello, la arqueología del conflicto carlista debe abandonar su posición marginal y avanzar hacia una consolidación propia. Para ello es necesario en primer lugar revertir la situación de olvido en la que se halla, tomarla en consideración y dotarla de prestigio mediante los cauces habituales: realización de ponencias, congresos, jornadas, publicaciones... proceso en el que reviste importancia la incorporación de más investigadores. Es necesaria una importante labor de sensibilización hacia las instituciones administrativas, custodias del patrimonio arqueológico, a las comunidades locales que interactúan día a día con él y a los propios arqueólogos, que en muchas ocasiones son ellos mismos quienes no toman en consideración elementos patrimoniales de época reciente como los que nos ocupan. También sería interesante que los historiadores, tradicionalmente centrados en las fuentes escritas, comenzaran a emplear las fuentes materiales existentes, que como hemos visto, son abundantes y ofrecen datos de interés.

Por último, decir que en el texto solamente se ha ofrecido una aproximación a este registro material, y además focalizado en yacimientos con una larga secuencia anterior, quedándose fuera los elementos ex novo durante la guerra, que como se ha visto en el estado de la cuestión apenas se han estudiado arqueológicamente y que sin duda merecen programas de estudio propios y profundos.

\section{AGRADECIMIENTOS}

Quería agradecer a los arqueólogos y arqueólogas que intervinieron los yacimientos tratados aquí. En especial a Sonía Aníbarro Sánchez y Félix Rafael Varón Hernández, que con sus comentarios han ayudado a la redacción de este texto. También al personal técnico del Bizkaia Arkeologia Museoa y del BIBAT Arkeologia Museoa. Por último, este estudio se ha desarrollado gracias a la ayuda de Gobierno Vasco para personal investigador no doctor.

\section{BIBLIOGRAFÍA}

Ajamil, F., 2003. Estudio Histórico-Arqueológico de la muralla de la villa de Peñacerrada-Urizaharra. Arkeoikuska 2003, 47-52.

Ajamil, F., 2011. Poblado y Templo de Nuestra Señora de Urizarra. Arkeoikuska 2011, 122-130.

Albi de la Cuesta, J., 2017. El Ejército Carlista del Norte. Desperta Ferro Ediciones, Madrid.

Aníbarro, S., 2005. Conveto de Carmelitas de San José de la Isla (Sestao). Arkeoikuska 2005, 349-352.

Aníbarro, S., 2006. Convento de San José de la Isla. Fase II (Sestao). Arkeoikuska 2006, 375-380.

Arrieta, A., 2015. Euskal Herriko Forteak. Berpizkundetik karlismora. Txalaparta, Tafalla.

Aurrekoetxea, U., 2010. San José de la Isla. Fase III. Arkeoikuska 2010, 275-283.

Barnard, S., 1998. Digging into Custer's Land Stand. Ventana Graphics, Huntington Beach. 
Buces, J., Moraza, A., 2011. Fuerte de Zumalakarregi. Arkeoikuska 2011, 321-324.

Cornelison, J., Cooper, T., 2002. An Archaeological Survey of the Chalmette Battlefield at Jean Lafitte Historical Park and Preserve. National Par Service, Southeast Archaeological Center, Tallahassee.

Cuerpo del Estado Mayor del Ejército, 1885. Narracción Militar de la Guerra Carlista de 1869 a 1876 (Vol. 4). Imprenta y Litografía del Depósito de la Guerra, Madrid.

Escribano, S., Roldán, I., Martín, G., 2016. Kastilozar. Arkeoikuska 2016, 103-105.

Fernández Bordegarai, J., 1992. Estudio histórico-arqueológico de la Villa de Salvatierra. Arkeoikuska 1992, 22-31.

Fernández Bordegarai, J., 2002. Zapatari, s/n (Salvatierra). Arkeoikuska 2002, 264-267.

Fernández Bordegarai, J., 2003. Extramuros de calle Zapatari (Salvatierra). Arkeoikuska 2003, 236-237.

Fernández Bordegarai, J., 2004. Estudio Histórico-Arqueológico de la muralla de Salvatierra. Tramo trasera del ayuntamiento (Salvatierra). Arkeoikuska 2004, 45-47.

Fernández-Bordegarai, J., Ajamil, F., 2002. Muralla de la villa de Peñacerrada (Peñacerrada-Urizaharra). Arkeoikuska 2002, 254-259.

Fusi, J., 2009. Violencias fratricidas. Carlistas y liberales en el siglo XIX. Gobierno de Navarra, Pamplona, pp. 9-14.

Geier, C., Potter, S., 2001. Acrchaeological Perspectives on the American Civil War. University Press of Florida, Gainesville.

Geier, C., Winter, S., 1994. Look to the Earth: Historical Archaeolog and the American Civil War. University of Tennessee Press, Knoxville.

Geier, C., Scott, D., Babits, L., 2014. From these honoured dead: Historical archaeology of the American Civil War. University Press of Florida, Gainesville.

Gil Zubillaga, E., 2001. El Fuerte en Nanclares de Oca. Arkeoikuska 2001, 174-179.

González-García, C., 2019. El Ejército del Centro en Castellón. Historia militar y arqueología de los campos de batalla en la Primera Guerra Carlista, 1833-1840. Tesis doctoral, Universidad de Salamanca.

González-Ruibal, A., 2016. Volver a las trincheras. Alianza, Madrid.

González-Ruibal, A., 2018. An Archaeology of the Contemporary Era: The Age of Destruction. Routledge.

González-Ruibal, A., 2020. The Archaeology of the Spanish Civil War. Routledge.

Haedera, Arqueología de Gestión, 2006a. Excavación arqueológica del convencto de Carmelitas de San José de la Isla (Sestao, Bizkaia). Memoria final de intervención.

Haedera, Arqueología de Gestión, 2006b. Intervención arqueológica Convento de Carmelitas del Desierto de San José. Fase II. Informe preliminar.

Haedera, Arqueología de Gestión, 2011. Actuación arqueológica en San José de la Isla. Fase III. Informe técnico preliminar.

Jankauskas, R., Signoli, M., Miliauskienè, Ž., 2006. Dental status of Napoleon's Great Army's (1812) mass burial of soldiers in Vilnius: childhood peculiarities and adult dietary habits. International Journal of Osteoarchaeology 16(4), 355-365.

Landa, C., Herández de Lara, O., 2020. Arqueología en campos de batalla. América Latina en perspectiva. Aspha, Buenos Aires.

Landa, C., \& Hernández de Lara, O., 2014. Sobre Campos de Batallas. Arqueología de conflictos bélicos en América Latina. Aspha, Buenos Aires.

Martín, G., 2017. Aproximación al estudio de tres fuertes de los conflictos carlistas en el entorno de Bilbao. Arkeogazte, Revista de Arqueología = Arkeologia Aldizkaria 7, 193-220.

Martín, G., 2019. Defendiendo la "Invicta Villa". Génesis y desarrollo de la"Línea de Bilbao y su ría y Abra" durante la Última Guerra Carlista (1872-1876). Vasconia, Cuadernos de historia y geografía 43, 33-73.

Moraza, A., Buces, J., García-Dalmau, M., 2012. Las fortificaciones de época carlista en Andoain. Leyçaur: Revista de estudios históricos de Andoain 12, 9-82.

Morín, J. E., 2004. Arqueología de la Guerrilla Antifranquista en Toledo. La 14ª División de la 1. ${ }^{a}$ Agrupación del Ejército de Extremadura y Centro. Bolskan 21, 181-188.

Navalón, V., Guimaraens, G., 2016. El valor de lo invisible. La fortificación liberal de Requena. Oleana 30, 123-140.

Neira, M., 2006. Plaza del Corazón de María (Bilbao). Arkeoikuska 2006, 385-389.

Neira, M., 2007. Convento de San Francisco. Plaza Corazón de María. Arkeoikuska 2007, 213-217.

Neira, M., Novoa, C., 2008. Convento de San Francisco. Plaza Corazón de María. Arkeoikuska 2008, 242-245.

Pellicer, J., 1875. Monte Esquinza. Recolección de tejas en terreno del enemigo para cubrir el "blockaus" del reducto "Marqués del Duero". Ilustración Española y Americana, 44, 405-406.

Pintos, S., 2020. Arqueología de campos de batalla de la Guerra de la Tirple ALianza. Caso de estudio: sitio Batalla de Yatay, provincia de Corrientes. En: Landa, C., Hernández de Lara, O., Arqueología en campos de batalla. América Latina en perspectiva, 193-226. Aspha, Buenos Aires.

Plata, A., 2016. El Castillo de Urizaharra Peñacerrada, Álava. Disponible en: http://www.vitoria-gasteiz.org.es/El-Castillo-de-Urizaharra-Alava-2.htm

Plata, A., Solaun, J., 2008. Plan de castillos de la CAV. Arkeoikuska 2008, 23-42.

Pujol, M., 2017. Exhumación y estudio de los restos de Ramón Vila Capdevila en el cementerio de Castellnou de Bages. Ebre 38, Revista Internacional de la Guerra Civil (1936-1939) 7, 197-212

QARK, Arqueología y Gestión Integral del Patrimonio Construido, 2010. Intervención arqueológica en la Plaza del Corazón de María (Bilbao).

Roldán, I., Escribano, S., 2015. Arqueología del Conflicto Carlista. Valoración del legado material de varios fuertes del Frente de Estella. Arkeogazte, Revista de Arqueología = Arkeologia Aldizkaria 5, 133-149.

Roldán, I., Escribano, S., 2017. Programa de investigación del patrimonio de las guerras carlistas en Navarra. Primeras intervenciones. Trabajos de arqueología navarra 29, 281-289.

Roldán, I., Martín, G., Escribano, S., 2019. The archaeology of civil conflict in nineteenth century Spain: material, social and 
mnemonic consequences of the Carlist Wars. World Archaeology 51(5), 709-723.

Rua, H., Gonçalves, A., Figueiredo, R., 2013. Assessmento of the Lines of Torres Vedras defensive system with visibility analysis. Journal of Archaeological Science 40, 2113-2123.

Rubio, X., Hernández-Cardona, F., 2012. La batalla de Talamanca, un combate del siglo XVIII. Revista Universitaria de Historia Militar 2, 29-48.

Saenz de Urturi, P., 2000. Convento de Santa Catalina de Badaya. Arkeoikuska 2000, 185-194.

Sáez-García, J., 2001. Fortificaciones liberales en el entorno de San Sebastián Durante la I Guerra Carlista. Sancho el Sabio: Revista de cultura e investigación vasca 14, 11-40.

Sáez-García, J., 2011. Los fuertes liberales de Urkabe y Arkale (Oiartzun). Vasconia 37, 263-277.

Saunders, N., Cornish, P. (Eds.), 2019. Modern Conflict and the Senses. Routledge.

Schofield, J., 2006. Combat archaeology. Material culture and modern conflict. Bristol Classical Press, Duckworth.

Scott, D., Fox, R., 1987. Archaeological insights into the Custer battlefield: an assesment of the 1984 field seson. Univesity of Oklahoma Press, Norman.

Suárez, P., Álvarez, V., 2016. Las fortificaciones olvidadas. Una propuesta metodológica desde la Arqueología para el estudio de las construcciones defensivas de la Guerra de la Independencia en Asturias. En: Gil, I.J. (ed.), Actas de las segundas jornadas sobre historia, arquitectura y construcción fortificada, 669-688. Madrid.
Varón, F., 2005. Barón de Benasque, 15 (Peñacerrada-Urizaharra). Arkeoikuska 2005, 263-267.

VV.AA., 2014. "El peligro te viene de arriba". Arqueología de una batalla durante la intervención estadounidense en la bahía de Matanzas, Cuba (1898). En: Landa, C., Hernández de Lara, O., Sobre campos de batalla. Arqueología de conflictos bélicos en América Latina, 191-234. Aspha, Buenos Aires.

VV.AA., 2014. Arqueología histórica de la Guerra del Paraná. La Vuelta de Obligado y el Tonelero. En: Landa, C., Hernández de Lara, O., Sobre campos de batalla. Arqueología de conflictos bélicos en América Latina, 75-108. Aspha, Buenos Aires.

VV.AA., 2017. Armamento de sitio en el castillo de Chinchilla (Albacete) durante la Guerra de la Independencia: Artillería y granadas de mano. Gladius: Estudios sobre armas antiguas, arte militar y vida cultural en oriente y occidente 37, 171-206.

VV.AA., 2020. La memoria anfibia: arqueología marítima de la guerra entre México y los Estados Unidos, 1846-1848. En: Landa, C., Hernández de Lara, O. Arqueología en campos de batalla. América Latina en perspectiva, 63-116. Aspha, Buenos Aires.

VV.AA., 2020. Zacatecas en la Revolución Mexicana: su cultura material. En: Landa, C., Hernández de Lara, O., Arqueología en campos de batalla. América Latina en perspectiva, 353376. Aspha, Buenos Aires.

Zamorano, C., 2020. La Guerra del Salitre: un primer acercamiento sobre estudios de campos de batalla en el contexto de la Campaña de Tarapacá de 1879. En: Landa, C., Hernández de Lara, O., Arqueología en campos de batalla. América Latina en perspectiva, 269-300. Aspha, Buenos Aires. 